\title{
Aversive Training Induces Both Presynaptic and Postsynaptic Suppression in Drosophila
}

\author{
Xiaofan Zhang, ${ }^{1}$ Nathaniel C. Noyes, ${ }^{1}$ Jianzhi Zeng, ${ }^{2}$ Y ulong Li, ${ }^{2}$ and Ronald L. Davis ${ }^{1}$ \\ ${ }^{1}$ Department of Neuroscience, The Scripps Research Institute Florida, Jupiter, Florida 33458, and ${ }^{2}$ State Key Laboratory of Membrane Biology, Peking \\ University School of Life Sciences, PKU-IDG/McGovern Institute for Brain Research, Peking-Tsinghua Center for Life Sciences, Chinese Institute for Brain \\ Research, Beijing 100871, China
}

The $\alpha^{\prime} \beta^{\prime}$ subtype of Drosophila mushroom body neurons (MBn) is required for memory acquisition, consolidation and early memory retrieval after aversive olfactory conditioning. However, in vivo functional imaging studies have failed to detect an early forming memory trace in these neurons as reflected by an enhanced G-CaMP signal in response to presentation of the learned odor. Moreover, whether cellular memory traces form early after conditioning in the mushroom body output neurons (MBOn) downstream of the $\alpha^{\prime} \beta^{\prime}$ MBn remains unknown. Here, we show that aversive olfactory conditioning suppresses the calcium responses to the learned odor in both $\alpha^{\prime} 3$ and $\alpha^{\prime} 2$ axon segments of $\alpha^{\prime} \beta^{\prime}$ MBn and in the dendrites of $\alpha^{\prime} 3$ MBOn immediately after conditioning using female flies. Notably, the cellular memory traces in both $\alpha^{\prime} 3 \mathrm{MBn}$ and $\alpha^{\prime} 3 \mathrm{MBOn}$ are short-lived and persist for $<30 \mathrm{~min}$. The suppressed response in $\alpha^{\prime} 3 \mathrm{MBn}$ is accompanied by a reduction of acetylcholine (ACh) release, suggesting that the memory trace in postsynaptic $\alpha^{\prime} 3 \mathrm{MBOn}$ may simply reflect the suppression in presynaptic $\alpha^{\prime} 3 \mathrm{MBn}$. Furthermore, we show that the $\alpha^{\prime} 3 \mathrm{MBn}$ memory trace does not occur from the inhibition of GABAergic neurons via $\mathrm{GABA}_{\mathrm{A}}$ receptor activation. Because activation of the $\alpha^{\prime} 3 \mathrm{MBOn}$ drives approach behavior of adult flies, our results demonstrate that aversive conditioning promotes avoidance behavior through suppression of the $\alpha^{\prime} 3 \mathrm{MBn}-\mathrm{MBOn}$ circuit.

Key words: Drosophila; mushroom body; olfactory conditioning; suppression

\section{Significance Statement}

Drosophila learn to avoid an odor if that odor is repeatedly paired with electric shock. Mushroom body neurons (MBns) are known to be major cell types that mediate this form of aversive conditioning. Here we show that aversive conditioning causes a reduced response to the conditioned odor in an axon branch of one subtype of the MBn for no more than 30 min after conditioning, and in the dendrites of postsynaptic, MB output neurons (MBOns). Because experimenter-induced activation of the MBOn induces approach behavior by the fly, our data support a model that aversive learning promotes avoidance by suppressing the MBn-MBOn synapses that normally promote attraction.

\section{Introduction}

Animals learn to avoid a neutral stimulus that is repeatedly coupled with an unpleasant one. This type of learning, aversive associative learning, induces cellular memory traces in engram cells in the brain and changes the representation of the neutral stimulus (Davis, 2011; Tonegawa et al., 2015). In Drosophila, several memory traces detected with the calcium indicator G-CaMP have been

\footnotetext{
Received June 17, 2019; revised Sept. 18, 2019; accepted Sept. 22, 2019.

Author contributions:X.Z., N.C.N., and R.L.D. designed research; X.Z. and N.C.N. performed research; X.Z., N.C.N., and R.L.D. analyzed data; X.Z. and N.C.N. wrote the first draft of the paper; X.Z., N.C.N., and R.L.D. edited the paper; X.Z., N.C.N., and R.L.D. wrote the paper; J.Z. and Y.L. contributed unpublished reagents/analytic tools.

This work was supported by the National Institutes of Health (Grant 1R35NS097224 to R.L.D.). We thank the Fly Light Research Team at Janelia Research for providing ga/4 lines and the 20XUAS-shibire ${ }^{\text {ts }}$ line.

The authors declare no competing financial interests.

Correspondence should be addressed to Ronald L. Davis at rdavis@scripps.edu

https://doi.org/10.1523/JNEUROSCI.1420-19.2019

Copyright $\odot 2019$ the authors
}

observed in the mushroom body (MB), a brain region critical for olfactory learning and memory (Davis, 1993; Yu et al., 2006; Wang et al., 2008; Davis, 2011; Cervantes-Sandoval et al., 2013). These memory traces are detectable across discrete time periods extending from $30 \mathrm{~min}$ to several days after training. However, memory traces that form immediately in the MB after conditioning have not been detected with in vivo $\mathrm{Ca}^{2+}$ imaging.

The MB is composed of $\sim 2000$ intrinsic neurons in each hemisphere that integrates olfactory cues received from antennal lobe projection neurons with aversive or rewarding stimuli from two clusters (PPL1, PAM) of dopamine neurons (DAns) (Schwaerzel et al., 2003; Claridge-Chang et al., 2009; Mao and Davis, 2009; Aso et al., 2012; Burke et al., 2012; Liu et al., 2012). MBn are classified into three major subtypes: $\alpha^{\prime} \beta^{\prime}, \alpha \beta$, and $\gamma$ neurons, based on their birth order and projection patterns of their axons in the brain (Crittenden et al., 1998; Lee et al., 1999). The axons of $\alpha^{\prime} \beta^{\prime}$ and $\alpha \beta \mathrm{MBn}$ bifurcate and project within the 
A

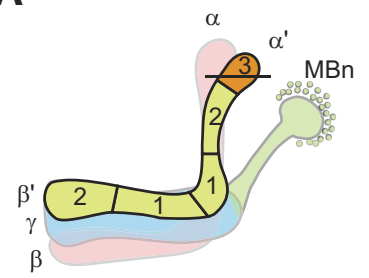

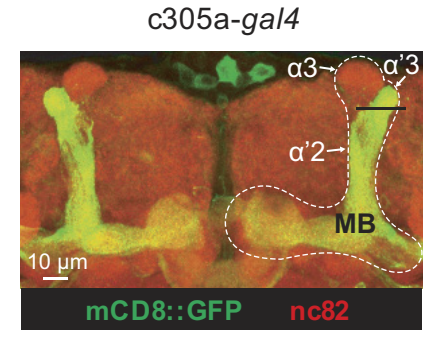

C
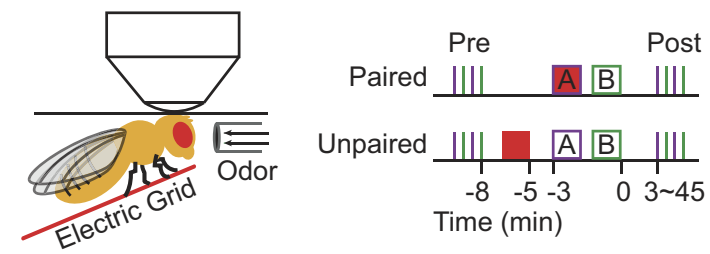

E

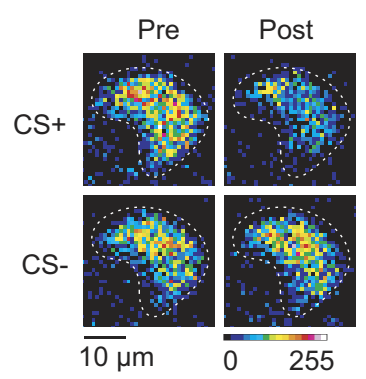

$\mathbf{F}$
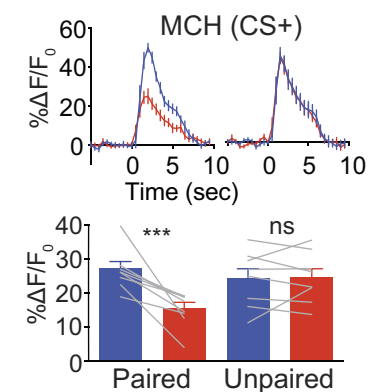

D
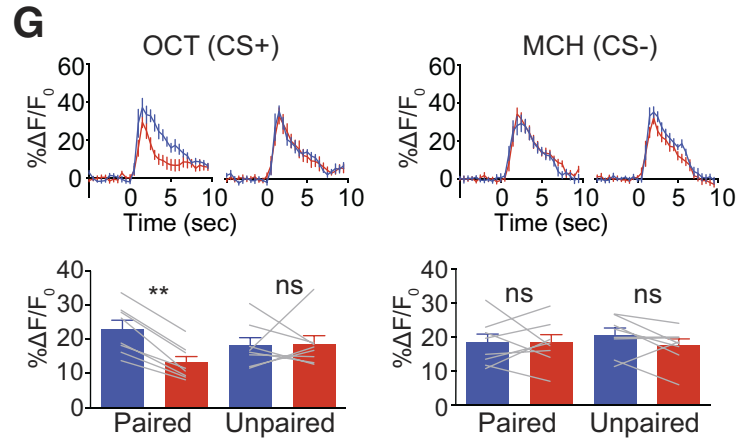
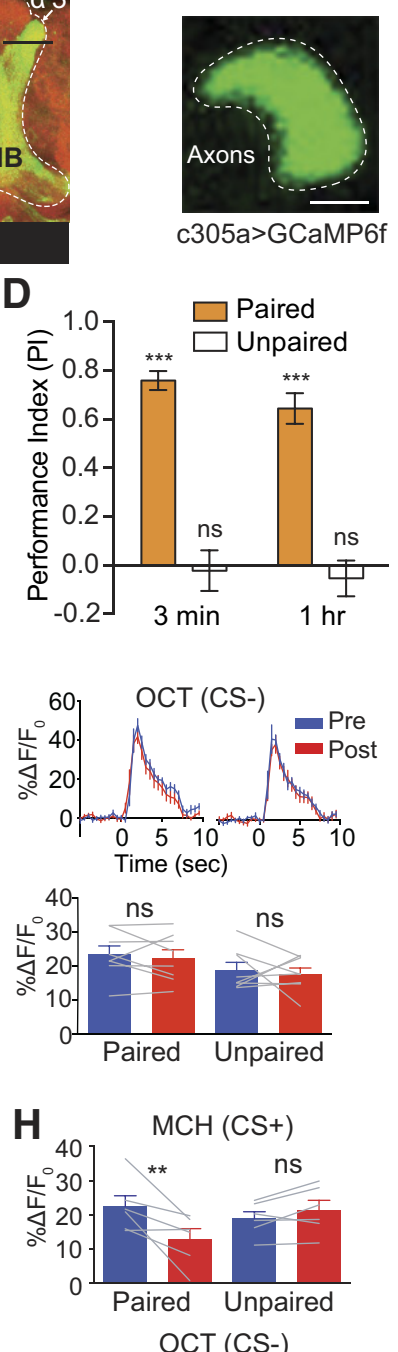

c305a>GCaMP6f

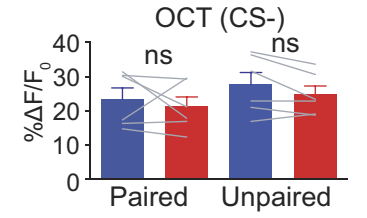

Figure 1. Pairing of odor and electric shock induces suppression to $\mathrm{CS}^{+}$odors in the $\alpha^{\prime} 3$ compartment. $\boldsymbol{A}$, Left, Schematic diagram of MB showing $\alpha^{\prime} \beta^{\prime}$ lobe neuropil and its five compartments from a frontal perspective. The line across $\alpha^{\prime} 3$ indicates the plane that was selected for imaging. Middle: morphology of $\mathrm{MB} \alpha^{\prime} \beta^{\prime}$ lobe neuropil visualized using c305a-gal4 > mCD8::GFP. Right, Representative in vivo image of GCaMP6f expression in the $\alpha^{\prime} 3$ region driven by c305a-gal4 (scale bar, $10 \mu \mathrm{m}$; brightness and contrast were adjusted for better visualization). $\boldsymbol{B}$, Schematic diagram of the in vivo training setup. The fly head is glued to a thin metal plate. There is a small hole in the plate through which the head cuticle is dissected and the brain can be imaged. The electric shock pulses are delivered to the fly through an electric grid contacting the fly's legs. Odor is delivered to the fly via glass pipette ( $\sim 3 \mathrm{~mm}$ diameter) whose tip is close to the antenna of the fly (arrows indicate odor flow direction). C, Paired and unpaired training protocol. In paired training, 1 min of 12 pulses electric shock and odor A $\left(\mathrm{CS}^{+}\right)$were presented simultaneously followed by odor $B\left(C S^{-}\right)$that was unpaired with shock. In unpaired training, 1 min of electric shock pulses was presented 3 min before odor A onset. Before training, two pulses of each odor were presented to the fly in alternating fashion for $5 \mathrm{~s}$ each with a $30 \mathrm{~s}$ interstimulus interval (Pre). After training, an identical set of odor pulses were presented to the fly (Post). D, Behavior performance of flies receiving paired and unpaired training protocols. Paired training induced robust memory performance at both $3 \mathrm{~min}$ and $1 \mathrm{~h}$ after training. However, unpaired training induced no memory at 3 min or $1 \mathrm{~h}$ after training. Mean $\pm \mathrm{SEM},{ }^{* * *} p<0.0001$, ns, not significant, $p \geq 0.4976$, one sample $t$ test against a theoretical mean of " $0, " n=6$. E, Pseudocolored peak responses of $\alpha^{\prime} 3$ axon segments to $\mathrm{CS}^{+}$and $\mathrm{CS}^{-}$before (Pre) and $3 \mathrm{~min}$ after (Post) paired training. $F$, Left top, Time course of GCaMP6f response in $\alpha^{\prime} 3$ to $\mathrm{CS}^{+}(\mathrm{MCH})$ during 5 s odor presentation before (Pre, blue) and $3 \mathrm{~min}$ after (Post, red) paired or unpaired training. Traces show the average response ( \pm SEM) across all flies tested. Bottom, Mean odor-evoked Pre and Post responses during the $5 \mathrm{~s}$ odor presentation. Right, Responses to the $\mathrm{CS}^{-}$(OCT). Data are shown as mean \pm SEM. ${ }^{* * *} p=0.0003$; ns, not significant, $p>0.9999$; repeated-measures two-way ANOVA with Bonferroni post hoc tests, $n=8$. G, Left top, Time course of GCaMP6f response in $\alpha^{\prime} 3$ to $\mathrm{OCT}\left(\mathrm{CS}^{+}\right)$during a 5 s odor presentation before (Pre, blue) and 3 min after (Post, red) paired or unpaired training. Traces show the average response ( \pm SEM) across all flies tested. Bottom, Mean odor-evoked Pre and Post responses during $5 \mathrm{~s}$ odor presentation.

vertical $\alpha^{\prime} / \alpha$ lobe and horizontal $\beta^{\prime} / \beta$ lobe neuropil, whereas the axons of $\gamma$ neurons project only within the horizontal $\gamma$ lobe neuropil. Although each of these MBn subtypes contributes to aversive olfactory memory, they do so at different times after conditioning (CervantesSandoval et al., 2013), with synaptic transmission from the $\alpha^{\prime} \beta^{\prime}$ and $\gamma \mathrm{MBn}$ required for robust expression of early and intermediate-term memory (immediate to $3 \mathrm{~h}$ ) and synaptic transmission from the $\alpha \beta \mathrm{MBn}$ having a more pronounced role for memory expression after $3 \mathrm{~h}$. Importantly, although the $\alpha^{\prime} \beta^{\prime} \mathrm{MBn}$ are required for memory acquisition, consolidation and early memory retrieval (Krashes et al., 2007; Cervantes-Sandoval et al., 2013), no immediate memory trace in $\alpha^{\prime} \beta^{\prime}$ MBns has been detected using in vivo $\mathrm{Ca}^{2+}$ imaging (Wang et al., 2008).

Five different types of MB output neurons (MBOns) tile the $\alpha^{\prime} \beta^{\prime}$ lobe with their dendritic trees into five discrete compartments, matching the tiling by axon terminals from presynaptic DAns (Mao and Davis, 2009; Aso et al., 2014a). Several of these MBOns are required for aversive memory or appetitive memory expression, and intermediate-term memory traces ( $\sim 1-2 \mathrm{~h}$ after conditioning) have been detected in some of these neurons (Séjourné et al., 2011; Owald et al., 2015). However, early memory traces have not been documented in these MBOns, and the relationship between such putative traces and those in the presynaptic MBn is unexplored. Connectome studies revealed that DAns make direct connection with MBOns (Eichler et al., 2017; Takemura et al., 2017), opening the possibility that MBOns form traces independently of the MBn.

Here, we show that a cellular memory trace forms immediately after conditioning in the MBn axons occupying the $\alpha^{\prime} 3$ compartment and in the downstream $\alpha^{\prime} 3$ MBOn. Functional $\mathrm{Ca}^{2+}$ imaging reveals that aversive conditioning suppresses subsequent responses to the learned odor in both the presynaptic $\alpha^{\prime} 3$ compartment and the postsynaptic $\alpha^{\prime} 3$ MBOn across a

$\leftarrow$

Right, Responses to the $\mathrm{CS}^{-}(\mathrm{MCH})$. Data are shown as mean \pm SEM. ${ }^{* *} p=0.0022 ; n s$, not significant, $p \geq 0.4230$; repeated-measures two-way ANOVA with Bonferroni post hoc tests, $n=8$. $\boldsymbol{H}$, Top, Mean odor-evoked Pre and Post responses during $5 \mathrm{~s}$ odor presentation to $\mathrm{MCH}\left(\mathrm{CS}^{+}\right)$with 6 pulses of $30 \mathrm{~V}$ electric shock training protocol. Bottom, Responses to the $\mathrm{CS}^{-}$(OCT). Mean \pm SEM, ${ }^{* *} p=0.0077$; ns, not significant, $p \geq 0.6267$; repeated-measures two-way ANOVA with Bonferroni post hoc tests, $n=6$. 
similar time period, suggestive of a causal relationship. In vivo ACh imaging revealed that the suppressed $\mathrm{Ca}^{2+}$ responses are accompanied by reduced $\mathrm{ACh}$ release in the $\alpha^{\prime} 3$ compartment, supporting the model that the $\alpha^{\prime} 3$ MBOn memory trace occurs from suppressed presynaptic activity. We also show that the conditioning-induced suppression in the $\alpha^{\prime} 3$ compartment does not occur from increased inhibition through the $\underline{R} e$ sistance to dieldrin ( $\mathrm{Rdl}) \mathrm{GABA}_{\mathrm{A}}$ receptor, indicating that mechanisms other than $\mathrm{Rdl}$ receptor activation are responsible for the suppression of activity.

\section{Materials and Methods}

Fly husbandry. Fly stocks were cultured on standard food at room temperature. Crosses were kept at $25^{\circ} \mathrm{C}$ with $70 \%$ relative humidity and a $12 \mathrm{~h}$ light, $12 \mathrm{~h}$ dark cycle except for the shibire ${ }^{\text {ts }}$ experiments in which flies were raised on standard food at $23^{\circ} \mathrm{C}$ until training and testing (see below for details). Fly lines used in this study include $w^{1118}$ (BDSC, 3605), c305agal4 (Krashes et al., 2007), MB027B split gal4 (Aso et al., 2014b), 20XUAS-IVS-GCaMP6f (Chen et al., 2013), 20XUAS-shibire ${ }^{\text {ts }}$ (Pfeiffer et al., 2012), UAS-mCD::GFP (BDSC, 32197), UAS-Rdli8-10 (Liu et al., 2007), and UASGACh4.4 (Jing et al., 2018).

Behavioral experiments. We used 2- to 6-dold flies of mixed gender for behavior experiments. Standard aversive olfactory associative conditioning was performed as described previously (Beck et al., 2000). Approximately 50-60 flies were equilibrated in a room dimly lit with red light and with $\sim 70 \%$ humidity for $>30 \mathrm{~min}$ in fresh food vials. Then they were loaded into a training tube where they received the following stimuli in sequence: $30 \mathrm{~s}$ air, $1 \mathrm{~min}$ of an odor $\left(\mathrm{CS}^{+}\right)$paired with 12 electric shock pulses at $90 \mathrm{~V}(1.25 \mathrm{~s}$ each pulse; 12 pulses, $30 \mathrm{~V}$ in Fig. $6 \mathrm{~B}), 30 \mathrm{~s}$ of air, 1 min of a second odor $\left(\mathrm{CS}^{-}\right)$without shocks, $30 \mathrm{~s}$ air. We used 4-methylcyclohexanol (MCH) and 3-octanol (OCT) as odors for conditioning. To measure 3 min memory, flies were transferred into a T-maze, where they were allowed to choose between two arms containing the two odors for $2 \mathrm{~min}$. The performance index (PI) was calculated as (number of flies choosing the correct arm) - (number of flies choosing the incorrect $\mathrm{arm}) /($ total number of flies). A PI $=1$ means that all flies choose the correct arm, and a PI $=0$ means that the flies choose equally between the two arms. To measure memory at a later time, flies were transferred back to food vial until testing. For shibire ${ }^{\text {ts }}$ experiments, flies were trained in $23^{\circ} \mathrm{C}$, then they were transferred to $30^{\circ} \mathrm{C}$ (for shibire ${ }^{\text {ts }}$ activation) or $23^{\circ} \mathrm{C}$ (Ctrl) immediately after training until testing of 15 min memory at that temperature.

In vivo imaging. We used a customized chamber for in vivo training and imaging (see Fig. $1 B$ ) similar to that used in a previous report (Berry et al., 2018). Briefly, a single female fly was aspirated into a $200 \mu \mathrm{l}$ pipette tip cut to allow only the head to be exposed. Females are used only because of their larger size. The proboscis of the fly was secured in the retracted position with myristic acid to reduce the movement of the brain during imaging. The fly was then located in a narrow slot cut from the lid of a $5 \mathrm{~cm}$ Petri dish. A small piece of stainless steel foil with a hole in it was glued to a $5 \mathrm{~cm}$ Petri dish and covered the slot and the fly to expose the head. The head was glued to the foil with UV glue; the antenna underneath the foil remained free of glue. A small optical window was cut in the head cuticle to expose the brain and the head was then covered with fresh saline containing the following (in mM): $124 \mathrm{NaCl}, 3 \mathrm{KCl}, 20 \mathrm{MOPS}, 1.5$ $\mathrm{CaCl}_{2}, 4 \mathrm{MgCl}_{2} \cdot 6 \mathrm{H}_{2} \mathrm{O}, 5 \mathrm{NaHCO}_{3}, 1 \mathrm{NaH}_{2} \mathrm{PO}_{4} \cdot \mathrm{H}_{2} \mathrm{O}, 10$ trehalose, 7 sucrose, and 10 glucose, $\mathrm{pH}$ 7.2. Then, the Petri dish with the fly was attached to a base platform with magnets. To deliver electric shock pulses to the fly, a custom shock platform made with shock grids used in standard aversive training was secured to the base platform so that the fly legs were in contact but with sufficient room so that the fly could temporarily break the contact.

The fly was positioned such that the $\alpha^{\prime}$ lobe neuropil was in the vertical line of the objective lens to facilitate distinguishing the $\alpha^{\prime} 3$ and $\alpha^{\prime} 2$ compartments. In this position, the $\alpha^{\prime} 3$ compartment appears first as a crescent-shaped object with successive $Z$ steps in the ventral direction. Moving ventrally, a donut-shaped ring comes into focus. We defined the $\alpha^{\prime} 3$ region as essentially half the distance between the dorsal tip of the $\alpha^{\prime}$ lobe neuropil and the ring. The ring disappears with deeper imaging, being replaced by a triangular region of fluorescence. We defined the $\alpha^{\prime} 2$ compartment for imaging purposes as the triangular region. Further down, the fluorescence region becomes circular and then eventually merges at the junction area with the $\beta^{\prime}$ lobe. These definitions are consistent with our immunostaining results showing the $\operatorname{MBn} \alpha^{\prime} 3 / \alpha^{\prime} 3$ MBOn compartment with MB027B split gal4 (see Fig. 4) and the MB compartments illustrated in the literature (Aso et al., 2014b).

To deliver odors (MCH and OCT) to the fly, $100 \mathrm{ml} / \mathrm{min}$ air stream was diverted from flowing through a $20 \mathrm{ml}$ glass vial containing $10 \mathrm{ml}$ of mineral oil to flow through a $20 \mathrm{ml}$ glass vial containing $10 \mathrm{ml}$ of $1 \times$ $10^{-3}$ dilution of odorant in mineral oil. This air stream was then blended into a $1000 \mathrm{ml} / \mathrm{min}$ fresh air stream before reaching the fly through a $\sim 3$ $\mathrm{mm}$ glass pipette positioned $\sim 1 \mathrm{~cm}$ from the fly's antenna. After dissection, the flies were allowed to rest for 3 min under the microscope before odor exposure. For GCaMP6f and GACh imaging, $5 \mathrm{~s}$ of each odor was delivered to the flies with a $30 \mathrm{~s}$ interstimulus interval to confirm that the fly was alive and responding. Then, each fly was presented with 2 pulses of $5 \mathrm{~s}$ odor $\mathrm{A}(\mathrm{MCH}$ or OCT) and 2 pulses of $5 \mathrm{~s}$ odor B (OCT or $\mathrm{MCH})$ ("Pre" response) in alternating order. Each odor stimulus was separated by $30 \mathrm{~s}$ of fresh air. In the paired training protocol, flies were trained using 

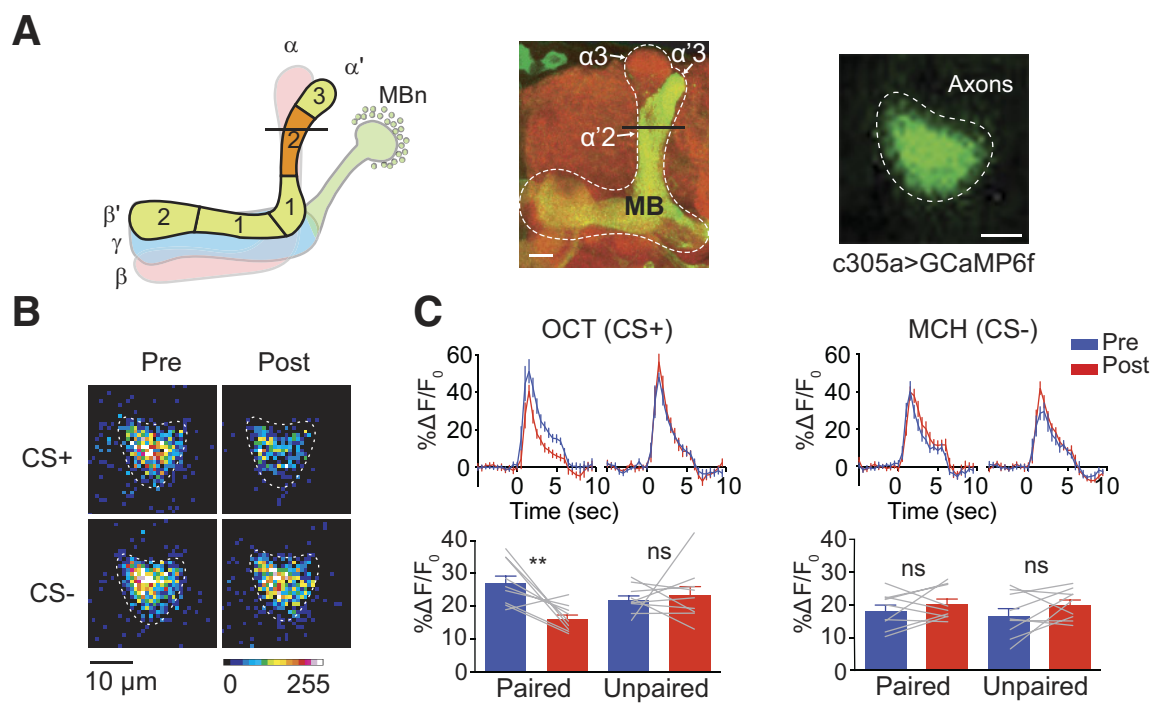

D
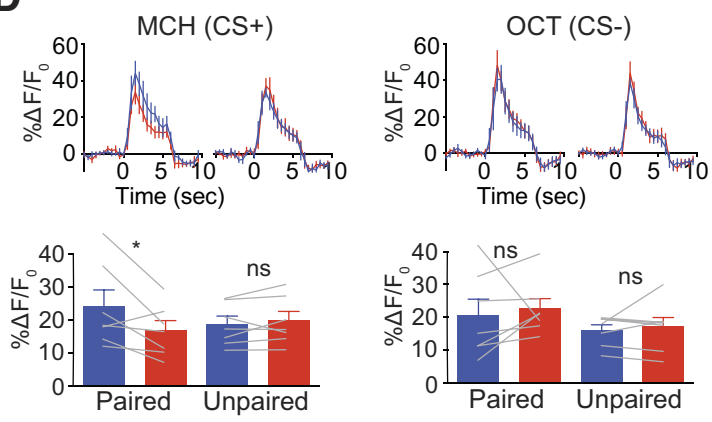

Figure 3. Pairing of odor and electric shock induces suppression to CS ${ }^{+}$odors in the $\alpha^{\prime} 2$ compartment. $\boldsymbol{A}$, Left, Schematic diagram of MB showing $\alpha^{\prime} \beta^{\prime}$ lobe neuropil and its five compartments. The line across $\alpha^{\prime} 2$ indicates the plane that was selected for imaging. Middle: morphology of $\mathrm{MB} \alpha^{\prime} \beta^{\prime}$ lobe visualized using c305a-gal4 $>\mathrm{mCD} 8::$ GFP. Right, Representative in vivo image of GCaMP6f expression in the $\alpha^{\prime} 2$ region driven by c305a-gal4 (scale bar, $10 \mu \mathrm{m}$; brightness and contrast were adjusted for better visualization). $\boldsymbol{B}$, Pseudocolored peak responses of $\alpha^{\prime} 2$ to $\mathrm{CS}^{+}$and $\mathrm{CS}^{-}$before (Pre) and 3 min after (Post) paired training. $\boldsymbol{C}$, Left top, Time course of GCaMP6f response in $\alpha^{\prime} 2$ to $\mathrm{CS}^{+}$(OCT) during 5 s odor presentation before (Pre, blue) and 3 min after (Post, red) paired or unpaired training. Traces show the average response ( $\pm S E M)$ across all flies tested. Bottom, Mean odor-evoked Pre and Post responses during $5 \mathrm{~s}$ odor presentation. Right, Responses to the $\mathrm{CS}^{-}(\mathrm{MCH})$. Data are shown as mean $\pm \mathrm{SEM} .{ }^{* *} p=$ 0.0085; ns, not significant, $p \geq 0.3129$; repeated-measures two-way ANOVA with Bonferroni post hoc tests, $n=9$. $\boldsymbol{D}$, Left top, Time course of GCaMP6f response in $\alpha^{\prime} 2$ to $\mathrm{MCH}\left(\mathrm{CS}^{+}\right)$during a 5 s odor presentation before (Pre, blue) and 3 min after (Post, red) paired or unpaired training. Traces show the average response ( \pm SEM) across all flies tested. Bottom, Mean odor-evoked Pre and Post responses during 5 s odor presentation. Right, Responses to the $\mathrm{CS}^{-}$(OCT). Data are shown as mean \pm SEM. ${ }^{*} p=0.0192$; $\mathrm{ns}$, not significant, $p>0.9999$; repeated-measures two-way ANOVA with Bonferroni post hoc tests, $n=7$.

a schedule identical to the protocol described for behavior (above) starting $5 \mathrm{~min}$ after the Pre odor exposure. For the unpaired training protocol, 1 min of electric shock pulses was presented 2 min after the Pre odor exposure (see Fig. 1C). Following training, the flies were presented with another set of 2 pulses of $5 \mathrm{~s}$ odor A and 2 pulses of $5 \mathrm{~s}$ odor B ("Post") identical to the "Pre" stimulation.

A Leica TCS SP8 confocal microscope with a $488 \mathrm{~nm}$ argon laser and $25 \times$ water-immersion objective was used for imaging. Imaging began 1 min before the first $5 \mathrm{~s}$ odor exposure and ended $30 \mathrm{~s}$ after last $5 \mathrm{~s}$ odor exposure for both Pre and Post recording. Images were collected with a $\mathrm{HyD}$ detector $(495-545 \mathrm{~nm})$ at $2 \mathrm{~Hz}$ at a resolution of $256 \times 256$ pixels. The baseline fluorescence $F_{0}$ was calculated as the average fluorescence across the $5 \mathrm{~s}$ before each odor exposure. Odor responses were calculated as the average fluorescence (normalized to $F_{0}$ for each frame) within $5 \mathrm{~s}$ odor presentation. Responses to the two pulses of the same odor in Pre and Post tests were then averaged as the Pre or Post response for each fly.

Immunostaining. For the immunostaining of GFP driven by $c 305 a-$ gal4 and MB027B-gal4 (see Figs. $1 A, 4 A$ ), whole brains were isolated and processed as described previously (Jenett et al., 2012). The primary antibodies used were rabbit anti-GFP (1:1000, Thermo Fisher Scientific, cat- alog \#A11122) and mouse anti-nc82 (1:50, DSHB, RRID:AB_2314866). The secondary antibodies used were goat anti-rabbit IgG conjugated to Alexa Fluor 488 (1:800, Thermo Fisher Scientific, catalog \#A11008) and goat anti-mouse IgG conjugated to Alexa Fluor 633 (1:500, Thermo Fisher Scientific, catalog \#A21052). Images were collected using a 10X objective with a Leica TCS SP8 confocal microscope with 488 and $633 \mathrm{~nm}$ laser excitation. The step size was $1 \mu \mathrm{m}$ and images were collected at a resolution of $515 \times 512$ pixels.

Experimental design and statistical analysis. For behavioral experiments, a mixture of both male and female flies was used. For in vivo imaging, only female flies were used because of their larger size. Statistical analyses were performed using Prism 5 (GraphPad). All tests were two tailed and confidence levels were set at $\alpha=0.05$. Nonparametric tests were used for imaging data, whereas parametric tests were used for olfactory memory scores (PI) as the values are normally distributed (Walkinshaw et al., 2015). Sample sizes and statistical tests used for each experiment are listed in the figure legends.

\section{Results}

Aversive olfactory conditioning transiently suppresses responses to the learned odor in the axons of $\boldsymbol{\alpha}^{\prime} \boldsymbol{\beta}^{\prime} \mathrm{MBn}$ Because prior behavioral studies demonstrated that the output of $\alpha^{\prime} \beta^{\prime} \mathrm{MBn}$ is required during acquisition, consolidation and retrieval of memories at early times after conditioning, we searched for memory traces in the axons of these neurons to identify the plasticity that might underlie this requirement (Krashes et al., 2007; Wang et al., 2008; Tan et al., 2010; Cervantes-Sandoval et al., 2013). There are five compartments in $\alpha^{\prime} \beta^{\prime}$ lobe neuropil (Fig. $1 A$ ), defined by the connections made with presynaptic modulatory DAn axons and the dendritic trees of postsynaptic MBOns (Mao and Davis, 2009; Aso et al., 2014a,b). We first focused on the $\alpha^{\prime} 3$ region. To detect possible changes in odor responses in the $\alpha^{\prime} 3$ compartment due to associative conditioning, we used in vivo functional imaging, training the flies under the confocal microscope and recording odor responses before (Pre) and after (Post) training (Fig. 1 $B, C$ ). We used a paired training protocol consisting of 12 pulses electric shock at $90 \mathrm{~V}$ (US) presented simultaneously with a 1 min presentation of an odor $\left(\mathrm{CS}^{+}\right)$followed by a second unpaired odor $\left(\mathrm{CS}^{-}\right)$with a $30 \mathrm{~s}$ interodor interval. To control for nonassociative effects, we used a protocol in which the $\mathrm{CS}^{+}$and US were explicitly unpaired (Fig. 1C). We validated our paired and unpaired training protocols using behavioral assays. The paired training protocol induced robust memory for the $\mathrm{CS}^{+}$at both $3 \mathrm{~min}$ and $1 \mathrm{~h}$ after training, whereas, the unpaired training protocol produced no memory at either time point (Fig. 1D).

Before conditioning, the MBn axons in the $\alpha^{\prime} 3$ compartment showed robust $\mathrm{Ca}^{2+}$ responses to the two odors used as $\mathrm{CS}^{+}$or $\mathrm{CS}^{-}$, 4-methylcyclohexanol (MCH) and 3-octanol (OCT), detected 
A

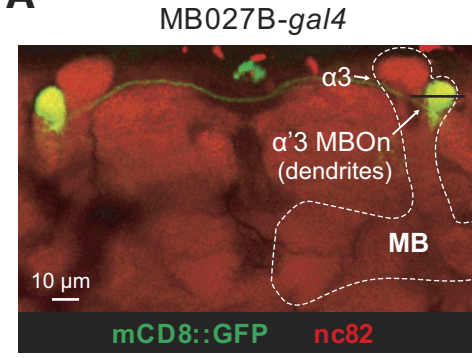

B

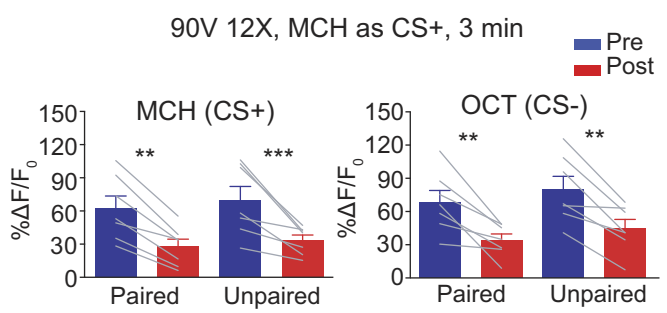

C

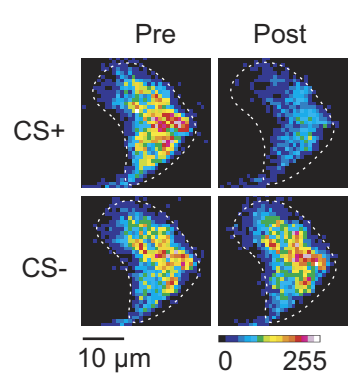

D
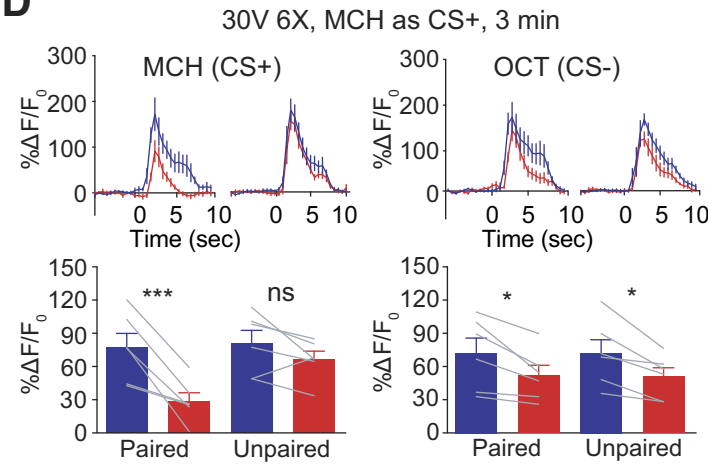

E

$30 \mathrm{~V} 6 \mathrm{X}, \mathrm{OCT}$ as $\mathrm{CS}+, 3 \mathrm{~min}$
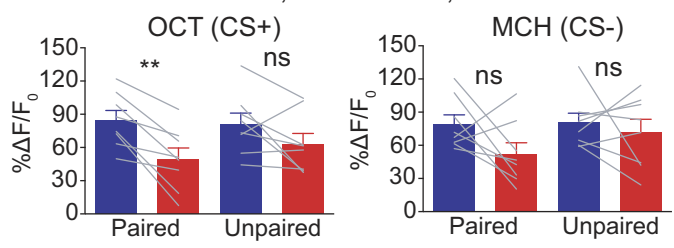

$\mathbf{F}$

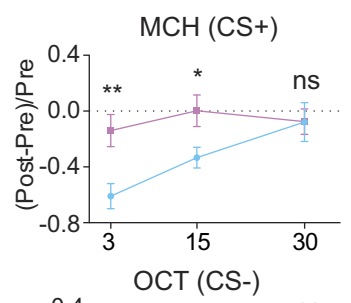

G

$90 \mathrm{~V} 12 \mathrm{X}, \mathrm{MCH}$ as $\mathrm{CS}+, 30 \mathrm{~min}$
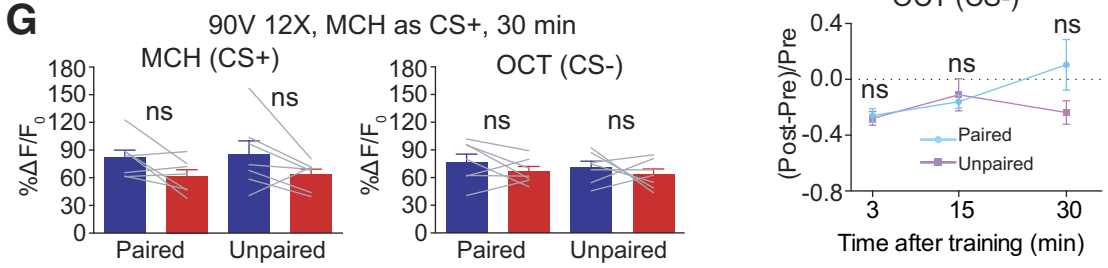

H
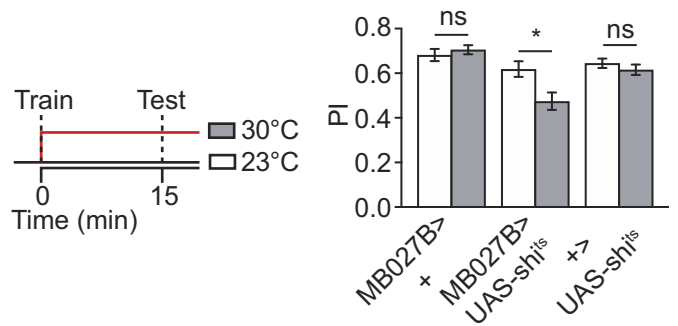

Figure 4. Pairing of odor and electric shock induces suppression in $\alpha^{\prime} 3 \mathrm{MBOn}$. $\boldsymbol{A}$, Morphology of postsynaptic MBOn that innervates $\alpha^{\prime} 3$ compartment visualized using MB027B split gal4 $>$ mCD8::GFP. The line across $\alpha^{\prime} 3$ MBOn indicates the plane that was selected for imaging. $\boldsymbol{B}$, Left, Mean odor-evoked GCaMP6f responses in $\alpha^{\prime} 3 \mathrm{MBOn}$ to $\mathrm{MCH}\left(\mathrm{CS}^{+}\right)$during 5 s odor presentation before (Pre, blue) and 3 min after (Post, red) paired or unpaired training with 12 pulses of $90 \mathrm{~V}$ electric shock. Right, Responses to OCT $\left(\mathrm{CS}^{-}\right)$. Data are shown as mean \pm SEM. ${ }^{* * *} p=0.0008,{ }^{* *} p \leq 0.0021$; repeated-measures two-way ANOVA with Bonferroni post hoc tests, $n=7$. C, Pseudocolored peak responses of $\alpha^{\prime} 3 \mathrm{MBOn}$ to $\mathrm{CS}^{+}$(MCH) and CS ${ }^{-}$(OCT) before (Pre) and 3 min after (Post) paired training with 6 pulses of 30 V electric shock. D, Left top, Time course of GCaMP6f response in $\alpha^{\prime} 3 \mathrm{MBOn}$ to $\mathrm{CS}^{+}(\mathrm{MCH})$ during 5 s odor presentation before (Pre, blue) and 3 min after (Post, red) paired or unpaired training with 6 pulses of $30 \mathrm{~V}$ electric shock. Traces show the average response ( \pm SEM) across all flies tested. Bottom, Mean odor-evoked Pre and Post responses during the 5 s odor presentation. Right, Responses to the $\mathrm{CS}^{-}(\mathrm{CCT})$. Data are shown as mean \pm SEM. ${ }^{* * *} p=0.0009,{ }^{*} p \leq 0.0119 ; \mathrm{ns}$, not significant, $p=0.2951$; repeated-measures two-way ANOVA with Bonferroni post hoc tests, $n=6$. $\boldsymbol{E}$, Left, Mean odor-evoked GCaMP6f responses in $\alpha^{\prime} 3 \mathrm{MBOn}$ to $0 \mathrm{CT}\left(\mathrm{CS}^{+}\right.$) during 5 s odor presentation before (Pre, blue) and 3 min after (Post, red) paired or unpaired training with 6 pulses of $30 \mathrm{~V}$ electric shock. Right, Responses to $\mathrm{MCH}\left(\mathrm{CS}^{-}\right)$. Data are shown as mean \pm SEM. ${ }^{* *} p=$ 0.0029; ns, not significant, $p \geq 0.1236$; repeated-measures two-way ANOVA with Bonferroni post hoc tests, $n=8$. $\boldsymbol{F}$, Change of odor response in $\alpha^{\prime} 3 \mathrm{MBO}$ n between Post and Pre at 3, 15, and 30 min after paired or unpaired training (CS $\left.{ }^{+}: \mathrm{MCH}, \mathrm{CS}{ }^{-}: O C T\right)$. The paired training-induced suppression of $\mathrm{CS}^{+}$persisted for at least $15 \mathrm{~min}$ and became nonsignificant at $30 \mathrm{~min}$. No significant with the reporter GCaMP6f expressed using the $\alpha^{\prime} \beta^{\prime}$ MBn driver, c305a-gal4 (Fig. $1 A, E)$. When we paired $\mathrm{MCH}\left(\mathrm{CS}^{+}\right)$with 12 pulses electric shock followed by OCT without shock $\left(\mathrm{CS}^{-}\right)$, we surprisingly observed a strong suppression of the $\mathrm{Ca}^{2+}$ response in $\alpha^{\prime} 3$ compartment to $\mathrm{MCH}$ but not OCT at $3 \mathrm{~min}$ after pairing (Fig. $1 E, F)$. This suppression was pairing specific since the suppression was not observed in unpaired group (Fig. $1 F$ ). In addition, the suppression was not odor specific since we observed a significant suppression using $\mathrm{OCT}$ as $\mathrm{CS}^{+}$and $\mathrm{MCH}$ as $\mathrm{CS}^{-}$(Fig. $1 G$ ). A weaker training protocol with 6 pulses of $30 \mathrm{~V}$ electric shock also induced significant suppression to $\mathrm{CS}^{+}$in $\alpha^{\prime} 3$ compartment (Fig. $1 H$ ).

We then measured the duration of the suppressed response. For this, we imaged the responses in the $\alpha^{\prime} 3$ compartment at 15, 30, and $45 \mathrm{~min}$ after paired and unpaired conditioning and compared them with preconditioning responses. We found that the suppression in the $\alpha^{\prime} 3$ compartment persisted to $15 \mathrm{~min}$ but was absent at 30 and $45 \mathrm{~min}$ after conditioning (Fig. $2 \mathrm{~A}, \mathrm{MCH}$ as $\mathrm{CS}^{+}$). We observed the same time course using $\mathrm{OCT}_{\text {as }} \mathrm{CS}^{+}$(Fig. $2 B)$. We note that the posttraining responses tended to increase with time when compared with pretraining responses for both odors and in both paired and unpaired groups (Fig. 2A,B). The source of this drift is unknown, but the critical measure is the difference between the paired and unpaired conditions. Together, these results demonstrate that aversive olfactory conditioning induces a very early cellular memory trace in the $\alpha^{\prime} 3$ compartment that is registered as a suppressed response specifically to the trained odor. This memory trace is transient and persists for $<30 \mathrm{~min}$.

$\leftarrow$

difference was observed in $\mathrm{CS}^{-}$between paired and unpaired groups at any time point. Data are shown as mean \pm SEM. ${ }^{* *} p=0.0087,{ }^{*} p=0.0411 ; \mathrm{ns}$, not significant, $p \geq 0.3095$; Mann-Whitney $U$ test, $n=6$. G, Mean odor-evoked GCaMP6f response at 30 min after training in $\alpha^{\prime} 3 \mathrm{MBOn}$ during $5 \mathrm{~s}$ odor presentation with 12 pulses of $90 \mathrm{~V}$ electric shock ( $\left(\mathrm{CS}^{+}: \mathrm{MCH}\right.$, $\left.\mathrm{CS}^{-}: \mathrm{OCT}\right)$. Data are shown as mean \pm SEM. ns, not significant, $p \geq 0.1372$; repeated-measures two-way ANOVA with Bonferroni posthoctests, $n=7$. $\boldsymbol{H}$, Blocking synaptic output of $\alpha^{\prime} 3 \mathrm{MBOn}$ immediately after training through testing impaired $15 \mathrm{~min}$ memory. Flies were trained at $23^{\circ} \mathrm{C}$, transferred to $30^{\circ} \mathrm{C}$ immediately after training for $15 \mathrm{~min}$, and tested at $30^{\circ} \mathrm{C}$. Data are shown as mean \pm SEM. ${ }^{*} p=0.0186 ; n$, not significant, $p>0.9999$; two-way ANOVA with Bonferroni post hoc tests, $n=6$. 
A

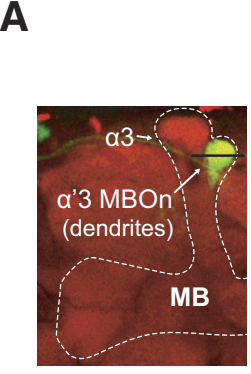

B
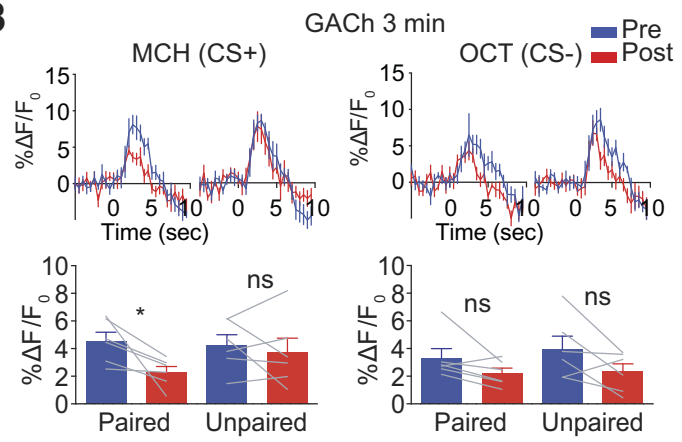

C

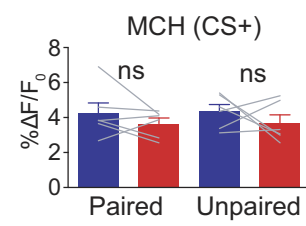

GACh $30 \mathrm{~min}$

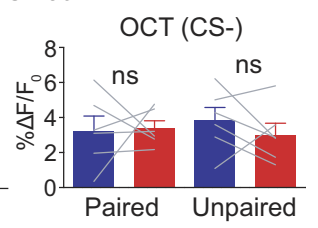

Figure 5. Pairing of odor and electric shock reduces ACh release in the $\alpha^{\prime} 3$ compartment. $A$, Morphology of postsynaptic MBOn that innervates $\alpha^{\prime} 3$ compartment visualized using MB027B split gal $4>\operatorname{mCD} 8:: G F P$. The line across $\alpha^{\prime} 3$ MBOn indicates the plane that was selected for imaging. $B$, Left top, Time course of GACh (ACh sensor) response in the dendrites of $\alpha^{\prime} 3 \mathrm{MBOn}$ to $\mathrm{CS}^{+}$(MCH) during 5 s odor presentation before (Pre, blue) and 3 min after (Post, red) paired or unpaired training with 6 pulses of $30 \mathrm{~V}$ electric shock. Traces show the average response ( \pm SEM) across all flies tested. Bottom, Mean odor-evoked Pre and Post responses during the $5 \mathrm{~s}$ odor presentation. Right, Responses to the $\mathrm{CS}^{-}(\mathrm{OCT})$. Data are shown as mean $\pm \mathrm{SEM} .{ }^{*} p=0.0457$; ns, not significant, $p>0.9999$ for MCH in unpaired group, $p=0.3003$ for OCT in paired group and $p=0.0856$ for OCT in unpaired group; repeated-measures two-way ANOVA with Bonferroni post hoc tests, $n=6$. C, Mean odor-evoked GACh response at $30 \mathrm{~min}$ after training in the dendrites of $\alpha^{\prime} 3 \mathrm{MBO}$ during 5 s odor presentation with 6 pulses of $30 \mathrm{~V}$ electric shock ( $\mathrm{CS}^{+}: \mathrm{MCH}, \mathrm{CS}^{-}: \mathrm{OCT}$ ). Data are shown as mean \pm SEM. ns, not significant, $p \geq 0.6660$; repeated-measures two-way ANOVA with Bonferroni post hoc tests, $n=6$.

The $\boldsymbol{\alpha}^{\prime} \boldsymbol{\beta}^{\prime} \mathrm{MBn}, \boldsymbol{\alpha}^{\prime} 2$ neuropil compartment also shows conditioning-induced suppression in $\mathrm{CS}^{+}$odor responses

We next investigated whether the conditioning-induced suppression is specific to the $\alpha^{\prime} 3$ compartment or whether it generalizes to the vertical axons of the $\alpha^{\prime} \beta^{\prime} \mathrm{MBn}$. Like the axonal segments in the $\alpha^{\prime} 3$ compartment, those in the $\alpha^{\prime} 2$ compartment region (Fig. $3 A$ ) are also innervated by DAn of the PPL1 cluster (Mao and Davis, 2009; Aso et al., 2014a). In addition, activation of $\alpha^{\prime} 3$ MBOn and $\alpha^{\prime} 2$ MBOn both drive approach behavior, shown by the fly's preference to the light used to stimulate these neurons with CsChrimson (Aso et al., 2014a). Indeed, we observed a significant suppression to the $\mathrm{CS}^{+}$in the $\alpha^{\prime} 2$ compartment at $3 \mathrm{~min}$ using the paired but not the unpaired conditioning protocol (Fig. $3 B, C, \mathrm{OCT}_{\text {as }} \mathrm{CS}^{+}$). In addition, the suppression generalized to the other odor when used as $\mathrm{CS}^{+}$(Fig. 3D). The $\alpha^{\prime} 1$ compartment may also show a similar memory trace, but this region was difficult to resolve. The combined results reveal that olfactory aversive conditioning suppresses $\mathrm{Ca}^{2+}$ responses in the axon segments of the $\alpha^{\prime} \beta^{\prime}$ MBn residing in the $\alpha^{\prime} 3$ and $\alpha^{\prime} 2$ compartments.

\section{Aversive olfactory conditioning transiently suppresses responses to the learned odor in the dendrites of $\alpha^{\prime} 3 \mathrm{MBOn}$} Because the dendrites of the $\alpha^{\prime} 3$ MBOn innervate the $\alpha^{\prime} 3$ compartment (Fig. 4A), we wondered whether the suppressed responses of the axonal segments of $\alpha^{\prime} \beta^{\prime} \mathrm{MBn}$ in the $\alpha^{\prime} 3$ compartment would be transmitted to the $\alpha^{\prime} 3 \mathrm{MBOn}$. This was the simplest model, assuming direct innervation and transfer of information from MBn to MBOn. However, given the complexity of this neuropil, which contains the processes of $\alpha^{\prime} \beta^{\prime}$ MBn, PPL1 DAn, $\alpha^{\prime} 3 \mathrm{MBOn}$, octopaminergic/GABAergic anterior paired lateral (APL) neurons (Liu and Davis, 2009; Wu et al., 2013) and serotonergic/GABAergic dorsal paired medial (DPM) neurons
(Lee et al., 2011; Haynes et al., 2015), any signal from $\alpha^{\prime} \beta^{\prime} \mathrm{MBn}$ may easily be modulated in some way.

We expressed GCaMP6f specifically in the $\alpha^{\prime} 3$ MBOn with the split gal4 MB027B (Fig. 4A) and monitored responses before and after conditioning. The standard pairing protocol of 12 pulses, $90 \mathrm{~V}$ of electric shock along with $1 \mathrm{~min}$ of $\mathrm{CS}^{+}$ $(\mathrm{MCH})$ induced a strong suppression of $\alpha^{\prime} 3 \mathrm{MBOn}$ responses to both the $\mathrm{CS}^{+}$and $\mathrm{CS}^{-}$at 3 min after conditioning (Fig. 4B). This suppression was also observed with both odors in the unpaired groups. We wondered whether this strong, $\mathrm{CS}^{+} / \mathrm{CS}^{-}$ and paired/unpaired-independent suppression might mask an associative conditioninginduced memory trace in $\alpha^{\prime} 3 \mathrm{MBOn}$. To explore this possibility, we used weaker training protocols with reduced shock voltage and fewer pulses to minimize the hypothetical nonspecific suppression.

We found that nonspecific suppression was weak or undetectable using six shock pulses of $30 \mathrm{~V}$, and that pairing and $\mathrm{CS}^{+}(\mathrm{MCH})$ odor-specific suppression was revealed (Fig. 4C,D). We did observe a slight but significant decrease in the responses to OCT $\left(\mathrm{CS}^{-}\right)$in both the paired and unpaired groups (Fig. 4D), however, there was no significant difference in the magnitude of the decrease between the two groups (Fig. 4F, 3 min time point). Again, the training-induced suppression in $\alpha^{\prime} 3$ MBOn was specific to the $\mathrm{CS}^{+}$odor, since we observed the same result when we used OCT as $\mathrm{CS}^{+}$and $\mathrm{MCH}$ as $\mathrm{CS}^{-}$(Fig. 4E). Together, these results show that olfactory aversive conditioning also suppresses the $\mathrm{CS}^{+}$odor response properties of the postsynaptic $\alpha^{\prime} 3$ MBOn immediately after conditioning.

Given that DAn and other neuron types innervate the $\alpha^{\prime} 3$ compartment, we considered the possibility that training may induce distinct memory traces in presynaptic $\alpha^{\prime} 3 \mathrm{MBn}$ axons and postsynaptic $\alpha^{\prime} 3 \mathrm{MBOn}$ dendrites. To address this possibility, we studied the duration of $\alpha^{\prime} 3$ MBOn suppression to the conditioned odor and compared it with the time course for suppression in presynaptic $\alpha^{\prime} 3$ axons. Using the 6 pulses, $30 \mathrm{~V}$ conditioning schedule, we found that the suppression in the $\alpha^{\prime} 3$ MBOn dendrites persisted for at least 15 but not $30 \mathrm{~min}$ after conditioning using $\mathrm{MCH}$ as $\mathrm{CS}^{+}$(Fig. $4 F$ ). There was no significant difference between paired and unpaired group responses to the $\mathrm{CS}^{-}$at either time point (Fig. $4 F$ ). We worried that a US consisting of 6 pulses at $30 \mathrm{~V}$ may be too weak to induce suppression lasting at least $30 \mathrm{~min}$ after conditioning, so we performed an experiment using 12 pulses of $90 \mathrm{~V}$ as the US. Using this stronger conditioning paradigm, we failed to observe significant suppression in the $\alpha^{\prime} 3 \mathrm{MBOn}$ dendrites at $30 \mathrm{~min}$ after conditioning (Fig. 4G). We conclude that the suppressed response to the conditioned odor in the dendrites of the $\alpha^{\prime} 3 \mathrm{MBOn}$ follows the same time course as that observed in the MBn axonal segments in the $\alpha^{\prime} 3$ compartment.

\section{Output of the $\alpha^{\prime} 3 \mathrm{MBOn}$ is required for normal memory performance early after conditioning}

Although prior studies revealed that $\alpha^{\prime} 3$ MBOn activation drives approach behavior (Aso et al., 2014a), the requirement of these 
neurons in the early phases of aversive memory expression remains unknown. The memory trace described here and its time course suggests that the $\alpha^{\prime} 3 \mathrm{MBOn}$ may be required for the formation of behavioral memory and/or its retrieval at early times after conditioning. We reasoned that if $\alpha^{\prime} 3 \mathrm{MBOn}$ output is disrupted during memory retrieval, then the training-induced difference between the $\mathrm{CS}^{+}$and $\mathrm{CS}^{-}$evoked $\alpha^{\prime} 3 \mathrm{MBOn}$ output will be eliminated, which will result in an impairment of memory expression.

To probe this issue, we expressed the temperature sensitive shibire ${ }^{\mathrm{ts}}$ transgene $\left(s h i^{\mathrm{ts}}\right)$ in $\alpha^{\prime} 3 \mathrm{MBOn}$ with MB027B-gal4 driver. When we blocked $\alpha^{\prime} 3$ MBOn output immediately after aversive training by elevating the temperature for $15 \mathrm{~min}$ before and during testing, we found a significant impairment in memory expression (Fig. $4 H$ ). These results indicate that the synaptic output of $\alpha^{\prime} 3 \mathrm{MBOn}$ is required for the expression of early memory, and further suggest that the short-lived cellular memory trace which forms in the $\alpha^{\prime} 3 \mathrm{MBn}$ axon segments and/or the $\alpha^{\prime} 3 \mathrm{MBOn}$, contributes to behavioral memory expression early after conditioning.

\section{Conditioning-induced suppression of calcium responses in} the $\alpha^{\prime} 3 \mathrm{MBn}$ axon segment is accompanied by reduced $\mathrm{ACh}$ release

The results presented above indicate that olfactory aversive conditioning suppresses the $\mathrm{Ca}^{2+}$ responses to $\mathrm{CS}^{+}$odor in both the presynaptic $\alpha^{\prime} 3 \mathrm{MBn}$ axon segments and in the postsynaptic $\alpha^{\prime} 3$ MBOn dendrites. The similar time courses for the suppression in both the presynaptic and postsynaptic elements (Figs. 2, 4F) is most consistent with the possibility that the postsynaptic memory trace is a reflection of the presynaptic memory trace. This model predicts that the reduced $\mathrm{Ca}^{2+}$ responses to the conditioned odor observed in the presynaptic $\alpha^{\prime} 3 \mathrm{MBn}$ axon segments translates into reduced neurotransmitter release and a corresponding reduction of $\mathrm{Ca}^{2+}$ responses in the postsynaptic dendrites. To probe this possibility, we measured the release of ACh in $\alpha^{\prime} 3$ compartment as detected by the dendrites of $\alpha^{\prime} 3 \mathrm{MBOn}$ after aversive conditioning.

We expressed an ACh sensor GACh (Jing et al., 2018) in $\alpha^{\prime} 3$ MBOn using MB027B-gal4 and imaged the postsynaptic $\alpha^{\prime} 3$ MBOn before and after conditioning with 6 pulses of $30 \mathrm{~V}$ electric shock (Fig. 5A). We found that pairing odor $(\mathrm{MCH})$ with electric shock significantly suppressed the GACh signal using the paired but not the unpaired protocol when measured at 3 min after conditioning (Fig. $5 B$ ). This suggests that paired conditioning leads to reduced $\mathrm{ACh}$ release in response to the $\mathrm{CS}^{+}$odor in $\alpha^{\prime} 3$ compartment. No suppression of GACh response to $\mathrm{CS}^{+}$was observed at $30 \mathrm{~min}$ after conditioning (Fig. 5C). Because the time window of reduced ACh release matches the time window of $\alpha^{\prime} 3$ $\mathrm{MBn} / \alpha^{\prime} 3 \mathrm{MBOn}$ suppressed $\mathrm{Ca}^{2+}$ responses, we conclude that the suppressed $\mathrm{Ca}^{2+}$ signal of the $\alpha^{\prime} 3 \mathrm{MBOn}$ dendrites likely occurs by reduced ACh release from the $\alpha^{\prime} 3 \mathrm{MBn}$ axon segments.

\section{Suppression in $\alpha^{\prime} 3 \mathrm{MBn}$ axon segments is not due to increased GABAergic inhibition through the $\operatorname{Rdl~GABA}_{A}$ receptor}

Many different cellular or network models can explain the reduced ACh release by the $\alpha^{\prime} \beta^{\prime} \mathrm{MBn}$ due to conditioning. One of the more attractive models envisions an increased inhibitory tone on the MBn due to conditioning. Part of the attraction of this inhibitory model stems from the broad innervation of the MB neuropil by the APL and DPM GABAergic neurons. To probe this model, we reduced GABAergic input by knocking down the Rdl $\left(\mathrm{GABA}_{\mathrm{A}}\right)$ receptor in $\alpha^{\prime} \beta^{\prime}$ neurons using RNAi (Liu and Davis,
A
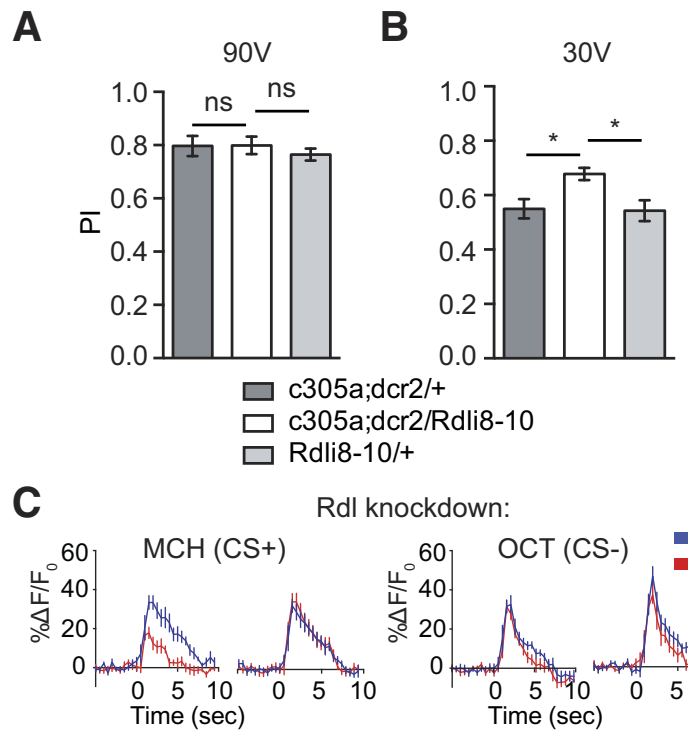

Rdl knockdown:
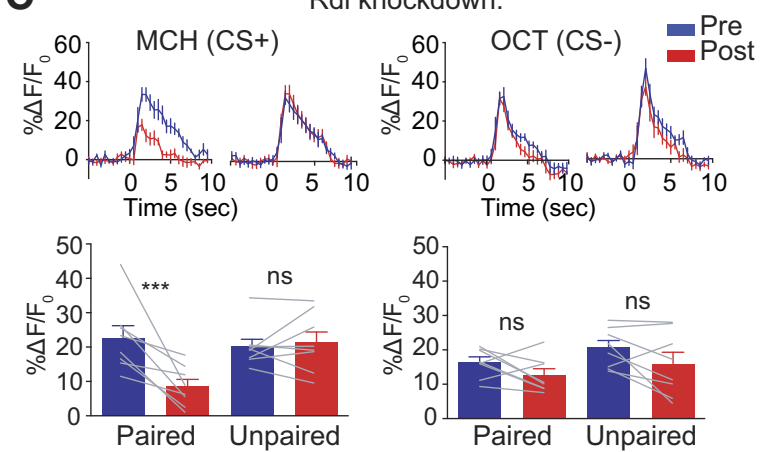

c305a;dcr2>GCaMP6f;Rdli8-10 (30V 12X)

\section{D}
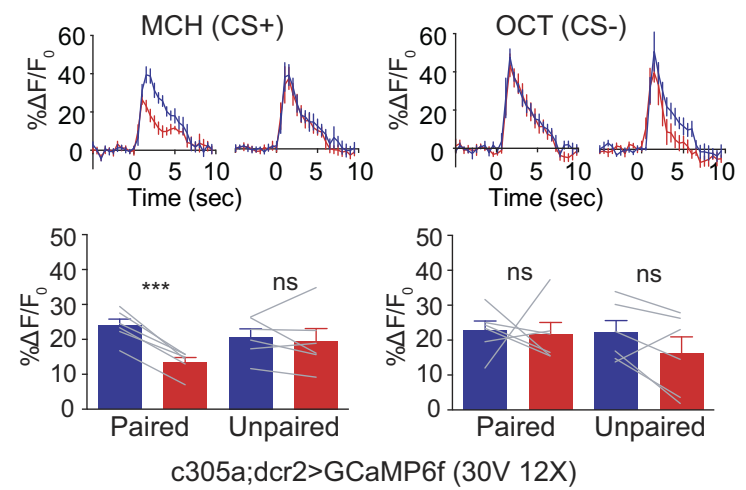

Figure 6. Suppression in $\alpha^{\prime} 3$ is not induced by GABAergic inhibition through Rdl GABA receptor. $A$, No change in 3 min memory with 12 pulses of $90 \mathrm{~V}$ electric shock when RdI (GABA receptor) was knocked down in $\alpha^{\prime} \beta^{\prime}$ MBn. Data are shown as mean \pm SEM. ns, Not significant; one-way ANOVA with Tukey's post hoc tests, $n=6$. B. There was significant enhancement of 3 min memory expression with 12 pulses of $30 \mathrm{~V}$ electric shock when Rdl was knocked down in $\alpha^{\prime} \beta^{\prime}$ MBn. Data are shown as mean \pm SEM. ${ }^{*} p \leq 0.0391$; one-way ANOVA with Tukey's post hoc tests, $n=6$. C, Knocking down Rdl did not impair the odor suppression to the $\mathrm{CS}^{+}$in the $\alpha^{\prime} 3$ compartment. Left top, Time course of GCaMP6f response in the $\alpha^{\prime} 3$ compartment to the $\mathrm{CS}^{+}(\mathrm{MCH})$ during a $5 \mathrm{~s}$ odor presentation before (Pre, blue) and 3 min after (Post, red) paired or unpaired training. Traces show the average response ( \pm SEM) across all flies tested. Bottom, Mean odor-evoked Pre and Post responses during $5 \mathrm{~s}$ odor presentation. Right, Responses to the $\mathrm{CS}^{-}$(OCT). Data are shown as mean \pm SEM. ${ }^{* * *} p=0.0009$; ns, not significant, $p \geq 0.1515$; repeated-measures two-way ANOVA with Bonferroni post hoc tests, $n=8$. $\boldsymbol{D}$, Control for Rdl knockdown in $\alpha^{\prime} \beta^{\prime}$ MBn. Left top, Time course of GCaMP6f response in the $\alpha^{\prime} 3$ compartment to the $\mathrm{CS}^{+}$(MCH) during 5 s odor presentation before (Pre, blue) and 3 min after (Post, red) paired or unpaired training. Traces show the average response ( \pm SEM) across all flies tested. Bottom, Mean odor-evoked Pre and Post responses during $5 \mathrm{~s}$ odor presentation. Right, Responses to the $\mathrm{CS}^{-}$(OCT). Data are shown as mean \pm SEM. ${ }^{* * *} p=0.0006$; ns, not significant, $p \geq 0.5049$; repeated-measures two-way ANOVA with Bonferroni post hoc tests, $n=6$. 
2009). When Rdl was reduced in $\alpha^{\prime} \beta^{\prime}$ neurons, we found that 3 min memory was enhanced using 12 pulses, $30 \mathrm{~V}$ as the US (Fig. $6 B$ ), consistent with previous reports (Liu et al., 2007; Liu and Davis, 2009). We failed to see this enhancement using 12 pulses, $90 \mathrm{~V}$ as US (Fig. 6A), probably due to a ceiling effect. We then measured the short-term cellular memory trace that forms in the $\alpha^{\prime} \beta^{\prime} \mathrm{MBn}$ with and without reduced Rdl expression. When the receptor expression was reduced using RNAi knockdown, we failed to observe any impairment of the $\alpha^{\prime} 3$ compartment memory trace with GCaMP6f (Fig. 6C), indicating that memory trace formation is independent of Rdl-mediated GABAergic inhibition. Instead, the suppression to the $\mathrm{CS}^{+}$odor in the knocked down group was perhaps more robust compared with the control (59\% vs $44 \%$ reduction; cf. Fig. $6 C, D$ ). This slight increase in suppression might underlie the enhanced 3 min memory when Rdl is reduced in $\alpha^{\prime} \beta^{\prime}$ neurons. These results argue against a model for a substantial role of increased inhibition to explain the suppression to $\mathrm{CS}^{+}$odors due to conditioning.

\section{Discussion}

Here, we provide evidence for the existence of immediate cellular memory traces that form in at least two adjacent segments of the axons in the vertical lobe neuropil of the $\alpha^{\prime} \beta^{\prime} \mathrm{MBn}$ and at least one ( $\alpha^{\prime} 3$ MBOn) of the corresponding output neurons. These memory traces, detected as decreased $\mathrm{Ca}^{2+}$ responses to the $\mathrm{CS}^{+}$ odor immediately after conditioning when compared with preconditioning responses, and persisting for $<30 \mathrm{~min}$ before the response properties return to the naive state, are consistent with the fact that $\alpha^{\prime} \beta^{\prime} \mathrm{MBn}$ are required for memory acquisition, consolidation and early memory retrieval (Krashes et al., 2007; Cervantes-Sandoval et al., 2013). Several other previously characterized early memory traces due to odor conditioning provide an interesting background to these newly discovered traces (Davis, 2011). The neurites of the DPM neurons innervating the vertical MB lobe neuropil exhibit an increased $\mathrm{Ca}^{2+}$ response to the learned odor from $\sim 30-70$ min after conditioning (Yu et al., 2005; Cervantes-Sandoval and Davis, 2012). A memory trace forms in the antennal lobe, registered as the recruitment of new projection neuron activity in response to the learned odor, that lasts $<10$ min after conditioning (Yu et al., 2004). The activity of GABAergic APL neurons that synapse in the vertical lobe neuropil of the MBn is suppressed for a period of a few minutes after conditioning (Liu and Davis, 2009). Further, in vivo functional imaging of the $\alpha^{\prime} \beta^{\prime} \mathrm{MBn}$ axons revealed an early memory trace displayed as increased $\mathrm{Ca}^{2+}$ influx by $30 \mathrm{~min}$ after conditioning that persists for at least $1 \mathrm{~h}$ (Wang et al., 2008; Tan et al., 2010; Cervantes-Sandoval and Davis, 2012). The action of these five memory traces, together along with other unknown traces, may provide the cellular modifications required for behavioral performance gains to be made across the first hour after conditioning. Memory traces in compartments other than $\alpha^{\prime} 3$ and/or their MBOns may underlie the requirement of $\alpha^{\prime} \beta^{\prime}$ MBn for memory retrieval beyond the first hour (Séjourné et al., 2011; CervantesSandoval et al., 2013; Owald et al., 2015).

However, the developmental trajectory of the memory traces forming in the $\alpha^{\prime} \beta^{\prime}$ MBn lobe is of additional interest. As indicated above, a cellular memory trace forms in these neurons by 30 min after conditioning that is manifested as an increased $\mathrm{Ca}^{2+}$ response to the conditioned odor (Wang et al., 2008; Tan et al., 2010). The data presented here show that the $\alpha^{\prime} \beta^{\prime}$ MBn axons become suppressed across the first $\sim 15 \mathrm{~min}$ after conditioning. The combined studies thus indicate that the $\mathrm{CS}^{+}$odor response properties in the $\alpha^{\prime} \beta^{\prime} \mathrm{MBn}$ axons are initially suppressed after conditioning but then become enhanced at later times. The time courses for the two cellular memory traces do not match exactly ( $0-15 \mathrm{~min}$ for the suppression and $\sim 30-60 \mathrm{~min}$ for the increase) given our current data showing no detectable increase at 30 or 45 min, but this is easily explained by variation in the strength of conditioning or minor technical differences between the two studies. Thus, the most parsimonious conclusion is that the vertical axon compartments of the $\alpha^{\prime} \beta^{\prime} \mathrm{MBn}$ initially exhibit a suppressed response to the $\mathrm{CS}^{+}$followed by an increased response with the transition from suppression to enhancement occurring somewhere between $\sim 30-45$ min after conditioning. How this evolution in response properties from negative to positive with time translates into behavioral memory expression remains unclear.

The suppressed responses to the $\mathrm{CS}^{+}$odor were found in both the axon segments of the $\alpha^{\prime} \beta^{\prime} \mathrm{MBn}$ and the dendrites of $\alpha^{\prime} 3$ MBOn. Given that activation of $\alpha^{\prime} 3$ MBOn drives approach behavior (Aso et al., 2014a), our results are consistent with the model that aversive conditioning promotes avoidance through suppressing the $\mathrm{MBn}-\mathrm{MBOn}$ circuits that signal positive valence, at least across the time that the MBOn responses are suppressed. Notably, the memory traces in $\alpha^{\prime} 3 \mathrm{MBn}$ and $\alpha^{\prime} 3 \mathrm{MBOn}$ persisted for the similar time, raising the question of whether the suppressed responses form independently or whether the $\alpha^{\prime} 3 \mathrm{MBOn}$ memory trace simply reflects the presynaptic one. Our data support the model in which the suppressed $\alpha^{\prime} \beta^{\prime} \mathrm{MBn}$ responses are simply transmitted to the MBOn from reduced synaptic activity: the suppressed $\mathrm{Ca}^{2+}$ response in $\alpha^{\prime} 3 \mathrm{MBn}$ axon compartment is correlated with reduced ACh release and the suppressed response in the $\alpha^{\prime} 3$ MBOn dendrites. Our behavioral data (Fig. 4H) suggest that if the early cellular memory traces that form in the $\alpha^{\prime} 3$ $\mathrm{MBn}-\mathrm{MBOn}$ circuit cannot be readout precisely, the expression of behavioral memory early after conditioning becomes impaired. However, we cannot exclude the possibility that memory traces can be formed independently in $\alpha^{\prime} 3 \mathrm{MBOn}$.

We formulated the hypothesis that the immediate suppression in $\alpha^{\prime} 3 \mathrm{MBn}$ axons after aversive conditioning might be due to enhanced GABAergic input to the $\alpha^{\prime} 3$ compartment in an effort to delineate the underlying mechanism. However, we failed to detect any impairment of the immediate suppression in $\alpha^{\prime} 3$ axonal compartment when we knocked down $\mathrm{Rdl} \mathrm{GABA}_{\mathrm{A}}$ receptor in $\alpha^{\prime} \beta^{\prime}$ neurons. Thus, our data argue against attributing the suppression in the $\alpha^{\prime} 3$ compartment to GABAergic inhibition through $\mathrm{GABA}_{\mathrm{A}}$ receptor.

\section{References}

Aso Y, Sitaraman D, Ichinose T, Kaun KR, Vogt K, Belliart-Guérin G, Plaçais PY, Robie AA, Yamagata N, Schnaitmann C, Rowell WJ, Johnston RM, Ngo TT, Chen N, Korff W, Nitabach MN, Heberlein U, Preat T, Branson KM, Tanimoto H, et al. (2014a) Mushroom body output neurons encode valence and guide memory-based action selection in Drosophila. Elife 3:e04580.

Aso Y, Hattori D, Yu Y, Johnston RM, Iyer NA, Ngo TT, Dionne H, Abbott LF, Axel R, Tanimoto H, Rubin GM (2014b) The neuronal architecture of the mushroom body provides a logic for associative learning. Elife 3:e04577.

Aso Y, Siwanowicz I, Bräcker L, Ito K, Kitamoto T, Tanimoto H (2010) Specific dopaminergic neurons for the formation of labile aversive memory. Curr Biol 20:1445-1451.

Beck CD, Schroeder B, Davis RL (2000) Learning performance of normal and mutant Drosophila after repeated conditioning trials with discrete stimuli. J Neurosci 20:2944-2953.

Berry JA, Phan A, Davis RL (2018) Dopamine neurons mediate learning and forgetting through bidirectional modulation of a memory trace. Cell Rep 25:651-662.e5.

Burke CJ, Huetteroth W, Owald D, Perisse E, Krashes MJ, Das G, Gohl D, 
Silies M, Certel S, Waddell S (2012) Layered reward signalling through octopamine and dopamine in Drosophila. Nature 492:433-437.

Cervantes-Sandoval I, Davis RL (2012) Distinct traces for appetitive versus aversive olfactory memories in DPM neurons of Drosophila. Curr Biol 22:1247-1252.

Cervantes-Sandoval I, Martin-Peña A, Berry JA, Davis RL (2013) Systemlike consolidation of olfactory memories in Drosophila. J Neurosci 33:9846-9854.

Chen TW, Wardill TJ, Sun Y, Pulver SR, Renninger SL, Baohan A, Schreiter ER, Kerr RA, Orger MB, Jayaraman V, Looger LL, Svoboda K, Kim DS (2013) Ultrasensitive fluorescent proteins for imaging neuronal activity. Nature 499:295-300.

Claridge-Chang A, Roorda RD, Vrontou E, Sjulson L, Li H, Hirsh J, Miesenböck G (2009) Writing memories with light-addressable reinforcement circuitry. Cell 139:405-415.

Crittenden JR, Skoulakis EM, Han KA, Kalderon D, Davis RL (1998) Tripartite mushroom body architecture revealed by antigenic markers. Learn Mem 5:38-51.

Davis RL (1993) Mushroom bodies and Drosophila learning. Neuron 11:1-14.

Davis RL (2011) Traces of Drosophila memory. Neuron 70:8-19.

Eichler K, Li F, Litwin-Kumar A, Park Y, Andrade I, Schneider-Mizell CM, Saumweber T, Huser A, Eschbach C, Gerber B, Fetter RD, Truman JW, Priebe CE, Abbott LF, Thum AS, Zlatic M, Cardona A (2017) The complete connectome of a learning and memory centre in an insect brain. Nature 548:175-182.

Haynes PR, Christmann BL, Griffith LC (2015) A single pair of neurons links sleep to memory consolidation in Drosophila melanogaster. Elife 4:e03868.

Jenett A, Rubin GM, Ngo TT, Shepherd D, Murphy C, Dionne H, Pfeiffer BD, Cavallaro A, Hall D, Jeter J, Iyer N, Fetter D, Hausenfluck JH, Peng H, Trautman ET, Svirskas RR, Myers EW, Iwinski ZR, Aso Y, DePasquale GM, et al. (2012) A GAL4-driver line resource for Drosophila neurobiology. Cell Rep 2:991-1001.

Jing M, Zhang P, Wang G, Feng J, Mesik L, Zeng J, Jiang H, Wang S, Looby JC, Guagliardo NA, Langma LW, Lu J, Zuo Y, Talmage DA, Role LW, Barrett PQ, Zhang LI, Luo M, Song Y, Zhu JJ, et al. (2018) A genetically encoded fluorescent acetylcholine indicator for in vitro and in vivo studies. Nat Biotechnol 36:726-737.

Krashes MJ, Keene AC, Leung B, Armstrong JD, Waddell S (2007) Sequential use of mushroom body neuron subsets during Drosophila odor memory processing. Neuron 53:103-115.

Lee PT, Lin HW, Chang YH, Fu TF, Dubnau J, Hirsh J, Lee T, Chiang AS (2011) Serotonin-mushroom body circuit modulating the formation of anesthesia-resistant memory in Drosophila. Proc Natl Acad Sci U S A 108:13794-13799.

Lee T, Lee A, Luo L (1999) Development of the Drosophila mushroom bodies: sequential generation of three distinct types of neurons from a neuroblast. Development 126:4065-4076.

Liu C, Plaçais PY, Yamagata N, Pfeiffer BD, Aso Y, Friedrich AB, Siwanowicz
I, Rubin GM, Preat T, Tanimoto H (2012) A subset of dopamine neurons signals reward for odour memory in Drosophila. Nature 488:512516.

Liu X, Davis RL (2009) The GABAergic anterior paired lateral neuron suppresses and is suppressed by olfactory learning. Nat Neurosci 12:53-59.

Liu X, Krause WC, Davis RL (2007) GABAA receptor RDL inhibits Drosophila olfactory associative learning. Neuron 56:1090-1102.

Mao Z, Davis RL (2009) Eight different types of dopaminergic neurons innervate the Drosophila mushroom body neuropil: anatomical and physiological heterogeneity. Front Neural Circuits 3:5.

Owald D, Felsenberg J, Talbot CB, Das G, Perisse E, Huetteroth W, Waddell S (2015) Activity of defined mushroom body output neurons underlies learned olfactory behavior in Drosophila. Neuron 86:417-427.

Pfeiffer BD, Truman JW, Rubin GM (2012) Using translational enhancers to increase transgene expression in Drosophila. Proc Natl Acad Sci U S A 109:6626-6631.

Schwaerzel M, Monastirioti M, Scholz H, Friggi-Grelin F, Birman S, Heisenberg M (2003) Dopamine and octopamine differentiate between aversive and appetitive olfactory memories in Drosophila. J Neurosci 23: 10495-10502.

Séjourné J, Plaçais PY, Aso Y, Siwanowicz I, Trannoy S, Thoma V, Tedjakumala SR, Rubin GM, Tchénio P, Ito K, Isabel G, Tanimoto H, Preat T (2011) Mushroom body efferent neurons responsible for aversive olfactory memory retrieval in Drosophila. Nat Neurosci 14:903-910.

Takemura S, Aso Y, Hige T, Wong A, Lu Z, Xu CS, Rivlin PK, Hess H, Zhao T, Parag T, Berg S, Huang G, Katz W, Olbris DJ, Plaza S, Umayam L, Aniceto R, Chang LA, Lauchie S, Ogundeyi O, et al. (2017) A connectome of a learning and memory center in the adult Drosophila brain. Elife 6:e26975.

Tan Y, Yu D, Pletting J, Davis RL (2010) Gilgamesh is required for rutabagaindependent olfactory learning in Drosophila. Neuron 67:810-820.

Tonegawa S, Liu X, Ramirez S, Redondo R (2015) Memory engram cells have come of age. Neuron 87:918-931.

Walkinshaw E, Gai Y, Farkas C, Richter D, Nicholas E, Keleman K, Davis RL (2015) Identification of genes that promote or inhibit olfactory memory formation in Drosophila. Genetics 199:1173-1182.

Wang Y, Mamiya A, Chiang AS, Zhong Y (2008) Imaging of an early memory trace in the Drosophila mushroom body. J Neurosci 28:4368-4376.

Wu CL, Shih MF, Lee PT, Chiang AS (2013) An octopamine-mushroom body circuit modulates the formation of anesthesia-resistant memory in Drosophila. Curr Biol 23:2346-2354.

Yu D, Ponomarev A, Davis RL (2004) Altered representation of the spatial code for odors after olfactory classical conditioning: memory trace formation by synaptic recruitment. Neuron 42:437-449.

Yu D, Keene AC, Srivatsan A, Waddell S, Davis RL (2005) Drosophila DPM neurons form a delayed and branch-specific memory trace after olfactory classical conditioning. Cell 123:945-957.

Yu D, Akalal DB, Davis RL (2006) Drosophila $\alpha / \beta$ mushroom body neurons form a branch-specific long-term cellular memory trace after spaced olfactory conditioning. Neuron 52:845-855. 